\title{
Impact of Machine Parameters on Knit Fabric GSM and Shrinkage
}

\author{
Md. Anisuzzaman Rassel, and Mohammad Mohsin Ul Hoque
}

\begin{abstract}
Knitted fabrics have a tendency to undergo some dimensional changes and GSM variation due to different knitting parameters. The investigation was carried out to relate the effect of different yarn counts, stitch lengths, machine gauge on fabric thickness variation and shrinkage behavior of the fabric. In this study the experimental results showed that fabric GSM varies as machine gauge changes by using same yarn count. On the contrary, when machine gauge and yarn count was fixed, the changes of fabric GSM was very negligible. For finer yarn count with different machine gauge GSM variation is more compared to coarser yarn count. But with same machine gauge GSM was very closer for both of finer and coarser yarn count. Fabric shrinkage both in lengthwise and widthwise is more fore finer yarn count than coarser yarn count. This study supports that, selection yarn count and calculation of stitch length was not only the way to meet buyer requirements regarding fabric thickness and shrinkage properties. The results found from this work will guide the determination to pick up right machine gauge, management of correct yarn diameter along with meticulous stitch length estimation.
\end{abstract}

Index Terms-Circular Knitting, Machine Gauge, GSM, Shrinkage, Stitch Length, Yarn Diameter, Knitting Parameters.

\section{INTRODUCTION}

Fabric is a material produced by natural or man-made fiber. There are different methods are available to produce fabric. Among of them knitting and weaving is the two main techniques to manufacture two different types of fabric which are used as work wear, casualwear, sportswear, leisurewear and other functional applications [1].

Knitting is the processes to produce knitted fabric by inter-looping yarn. Knitted fabrics are ideal for its extensibility, light weight, warmth, wrinkle resistance and ease of care properties. Knit fabrics are produced on different circular weft knitting machines with different conditions [2].

Knitted fabrics are classified into two main groups based on direction of yarn feeding and fabric types named weft and warp knitted fabrics. Machine Gauge, number of needles, fabric GSM, and yarn diameter as well as stitch length are very important factor prior to knit particular types of fabric $[3,4]$.

There are four primary structures are the base structures

Published on September 16, 2019

Md. Anisuzzaman Rassel working as Manager for Quality Assurance and Marketing department at Trust Text International, Dhaka (e-mail: anisuzzaman.rassel2003@gmail.com).

Mohammad Mohsin Ul Hoque, working as Faculty Member with the Department of Textile Engineering, National Institute of Textile Engineering and Research, (e-mail: mdmohsin.hoque@live.com). from which all weft knitted fabrics are produced. They are Jersey or plain, Rib, Interlock and Purl. Each of the structure is different from each other because of their particular combination of needle and cam arrangement [5].

In order to meet buyer requirement manufacturers are bound to produce fabric of certain GSM (Gram per Square Meter). GSM depends on yarn count, stitch length and machine gauge. Along with fabric GSM, dimensional stability of fabric is another important condition to get quality fabric for export [6].

Dimensional properties of the knitted fabric depend on the knitting machine parameters, selection of yarn count, stitch length and fabric finishing condition [7]. Whenever grey fabric is collected from immediate production, the characteristics of the weft knitted fabric became changed. It is not possible to control all the knitting parameters during fabric production [8].

Stitch length, wale spacing, course spacing, machine gauge, needle selection and needle timing, cam arrangement, yarn feeding system, fabric relaxation condition have a great impact on quality fabric production and the physical, mechanical and dimensional properties of the various knitted fabric structures [9].

The aim of this study is to identify the relationship of knitting parameters and their influences on fabric GSM and shrinkage percentage.

\section{Methodology Used}

\section{A. Determination of Knitting Machine Gauge}

Machine gauge represents number of needles per unit length of machine diameters. Selection of machine gauge depends upon yarn count, yarn type, twist factor and fiber composition. Yarn count primarily depends on the needle pitch. Machine gauge plays a vital role in the selection of yarn count which has an effect on fabric properties in terms of weight and appearance [10]. In order to obtain the best knitting performance for machine gauge is responsible for quality knit fabric production.

All the samples were knitted for a particular circular knitting machine for certain machine gauge and measured by counting the number of wales over several inches then dividing by the number of inches in the width of the sample.

\section{B. Determination of Fabric GSM}

In order to measure fabric weight per square meter following formula was used

Weight per square meter, in gram

$$
=\frac{\text { sample weight }(\text { in gram }) \times 10,000}{\text { area of sample in square centimeter }}
$$


Each and every sample undergoes by this formula to determine fabric GSM along with GSM cutter. By the use of GSM cutter, swatches were collected to weight and fond average weight. Then the result was multiplied by 100 to calculate GSM of the sample fabric. The area of round GSM cutter was $1 / 100$ square meters [11].

\section{Calculation of wales per inch and course per inch}

Ten inches' samples were unraveled to count the number of wales. The number of total wales was divided by ten to get the result of wales per inch. WPI was calculated from this equation of width.

Number of needles $=$ number of wales, and width is expressed in inch. Number of wales per inch=Total number of wales or number of needles/Width of the fabric in inches [12].

Counting glass was used to count course per inch. Total number of courses found in ten inches' sample was divided by ten to get the result of course per inch.

\section{Determination of Fabric Shrinkage}

Shrinkage is one of the leading quality problems which can cause problems during garments manufacturing and subsequent laundering process. The samples were washed in a washing machine and after then sample was rinsed. After rinsing, drying was completed with the help of a heated flat iron [13]. Shrinkage percentage was calculated by following formula

Shrinkage $=\frac{(\text { original measurement }- \text { final measurement })}{\text { original measurement }} \times 100 \%$

\section{RESULTS AND DISCUSSIONS}

The experimental results were investigated and listed in Table I, II and III.

\begin{tabular}{ccccc}
\multicolumn{5}{c}{ TABLE I: VARIATION OF GREY GSM } \\
\hline \hline Gauge & Diameter & Count & S/L Length & Grey GSM \\
\hline 18 & 34 & 26 & 2.88 & 253 \\
20 & 34 & 26 & 2.86 & 261 \\
24 & 34 & 26 & 2.82 & 272 \\
\hline \hline
\end{tabular}

Here 'gauge' means knitting machine gauge, 'diameter' refers knitting machine diameter expressed in inch, count refers yarn count in English count system and S/L Length refers stitch length in $\mathrm{mm}$.

The Figure1 showed that grey GSM is increased as machine gauge is increased whereas stitch length measurement for among knitting machines were adequately closer.

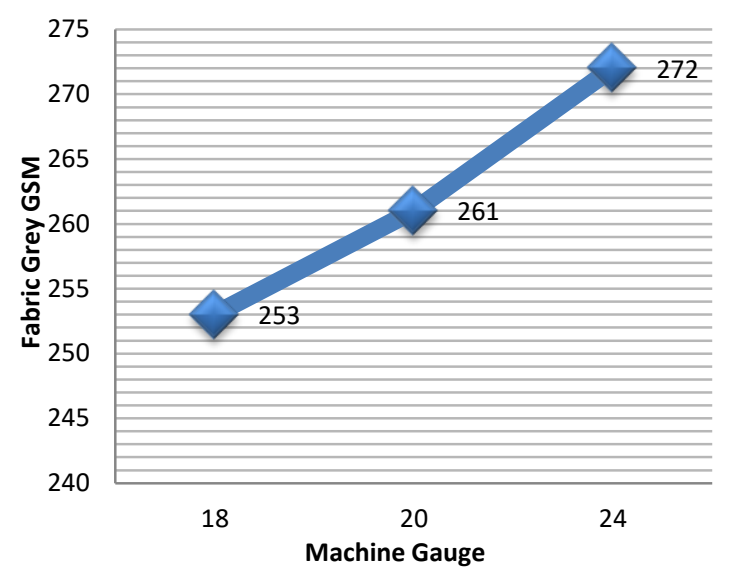

Fig.1. Effect of the interaction between machine gauge and fabric grey GSM for plain fabric.

TABLE II: GREY GSM IN SAME MACHINE GAUGE

\begin{tabular}{ccccc}
\hline \hline Gauge & Diameter & Count & S/L Length & Grey GSM \\
\hline 20 & 30 & 26 & 2.85 & 258 \\
20 & 30 & 26 & 2.85 & 261 \\
20 & 30 & 26 & 2.85 & 260 \\
\hline \hline
\end{tabular}

Here 'gauge' means knitting machine gauge, 'diameter' refers knitting machine diameter expressed in inch, count refers yarn count in English count system and S/L Length refers stitch length in $\mathrm{mm}$.

Figure 2 showed that for same machine gauge with same stitch length grey GSM were found very closer.

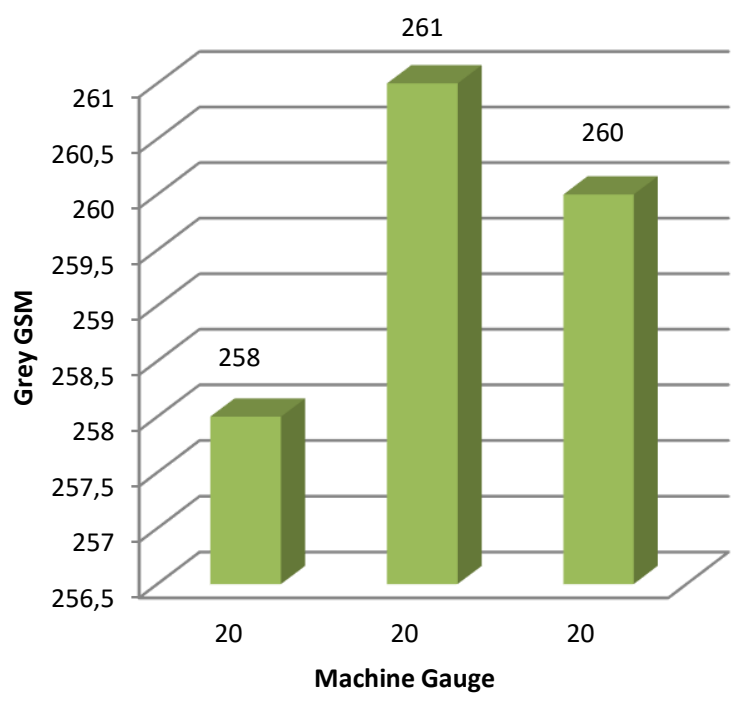

Fig.2. Effect of the interaction between same machine gauge and fabric grey GSM for plain fabric

TABLE III: VARIATION OF GREY GSM

\begin{tabular}{ccccc}
\hline \hline Gauge & Diameter & Count & S/L Length & Grey GSM \\
\hline 18 & 34 & 34 & 2.75 & 160 \\
20 & 34 & 34 & 2.70 & 172 \\
24 & 34 & 34 & 2.70 & 190 \\
\hline \hline
\end{tabular}

Here 'gauge' means knitting machine gauge, 'diameter' refers knitting machine diameter expressed in inch, count 
refers yarn count in English count system and S/L Length refers stitch length in $\mathrm{mm}$

Figure 3, stated that for finer yarn count with same machine diameter and closer stitch length grey GSM is increased as machine gauge is increased.

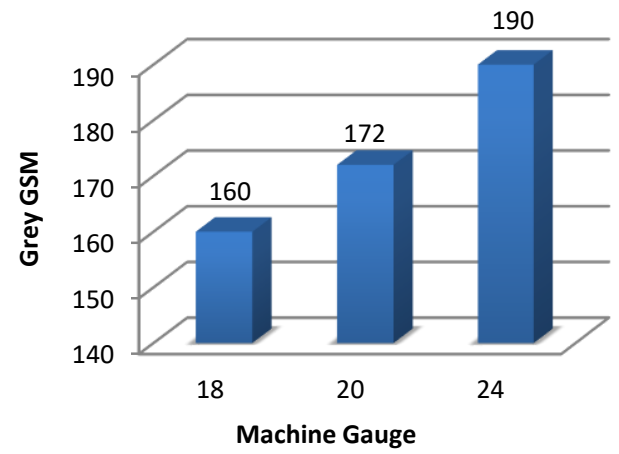

Fig. 3. Effect of the interaction between machine gauge and fabric grey GSM for plain fabric with finer yarn count

TABLE IV: GREY GSM IN SAME MACHINE GAUGE

\begin{tabular}{ccccc}
\hline \hline Gauge & Diameter & Count & S/L Length & Grey GSM \\
\hline 20 & 30 & 34 & 2.75 & 171 \\
20 & 30 & 34 & 2.75 & 168 \\
20 & 30 & 34 & 2.75 & 172 \\
\hline \hline
\end{tabular}

Here 'gauge' means knitting machine gauge, 'diameter' refers knitting machine diameter expressed in inch, count refers yarn count in English count system and S/L Length refers stitch length in $\mathrm{mm}$

Figure 4, showed that for same machine gauge with same stitch length with finer yarn count grey GSM were found very closer to each other

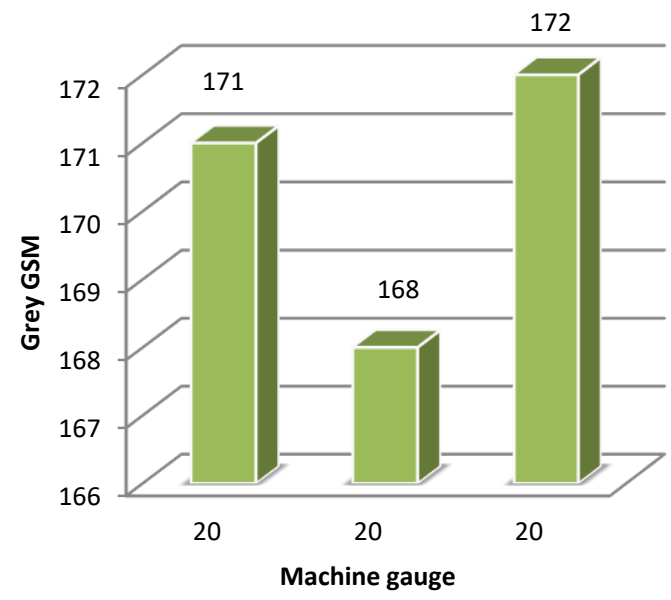

Fig. 4. Effect of the interaction between same machine gauge

TABLE V: VARIATION OF SHRINKAGE

\begin{tabular}{ccccc}
\hline \hline Gauge & Diameter & Count & L.Shrinkage & W.Shrinkage \\
\hline 18 & 30 & 26 & -3.0 & -5.0 \\
20 & 30 & 26 & -2.9 & -3.8 \\
24 & 30 & 26 & -2.8 & -4.5 \\
\hline \hline
\end{tabular}

Here 'gauge' means knitting machine gauge, 'diameter' refers knitting machine diameter expressed in inch, count refers yarn count in English count system and ' $L$. Shrinkage' refers lengthwise shrinkage percentage and ' $W$. Shrinkage refers widthwise shrinkage percentage

Figure 5, showed that as machine gauge changes, lengthwise shrinkage was very closer whether widthwise shrinkage percentage was significantly different with each other

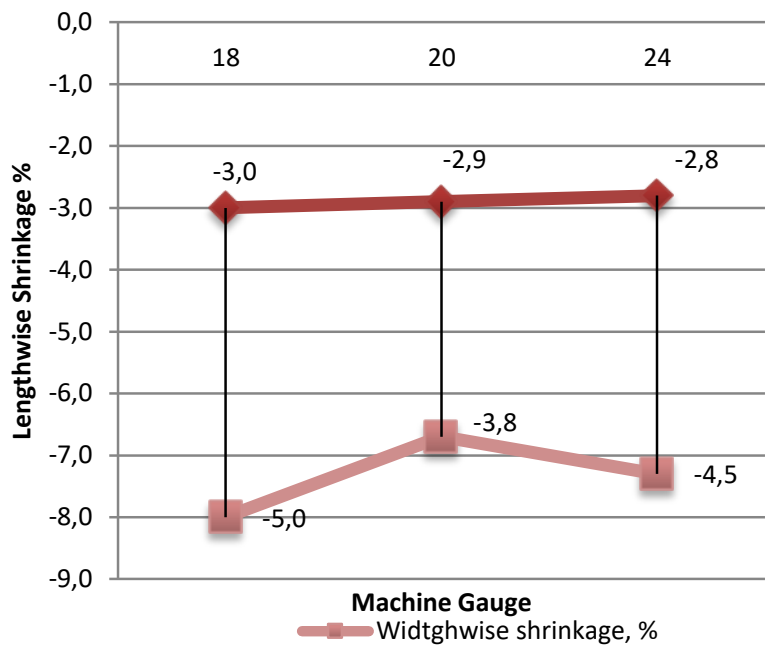

Fig. 5. Effect of the interaction between shrinkage percentage with different machine gauge (yarn count 26/s Ne)

TABLE VI: SHRINKAGE \% VARIES AS YARN COUNT CHANGES

\begin{tabular}{ccccc}
\hline \hline Gauge & Diameter & Count & L.Shrinkage & W.Shrinkage \\
\hline 18 & 30 & 34 & -7.0 & -5.5 \\
20 & 30 & 34 & -5.9 & -4.0 \\
24 & 30 & 34 & -6.0 & -4.8 \\
\hline \hline
\end{tabular}

Here 'gauge' means knitting machine gauge, 'diameter' refers knitting machine diameter expressed in inch, count refers yarn count in English count system and ' $L$. Shrinkage' refers lengthwise shrinkage percentage and 'W.Shrinkage refers widthwise shrinkage percentage

Figure 6 showed that for finer yarn count with different machine gauge, lengthwise and widthwise shrinkage percentage getting decreased as machine gauge increased.

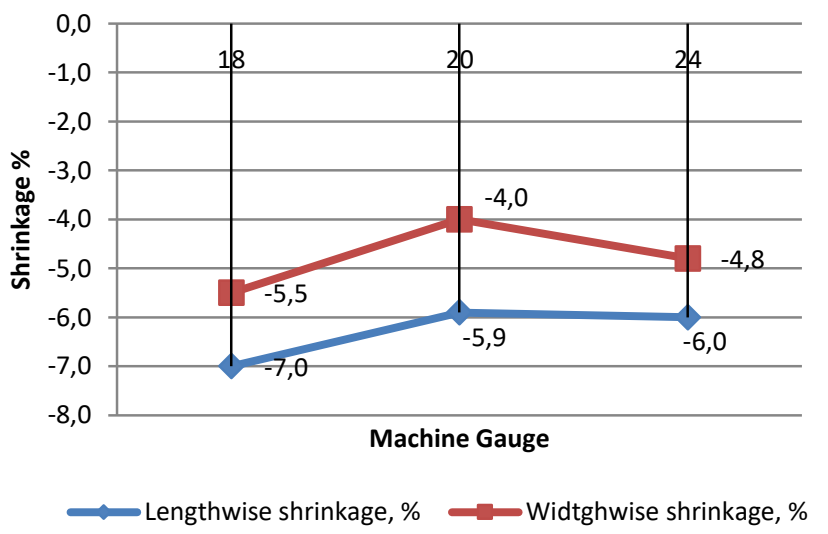

Fig. 6. Effect of the interaction between shrinkage percentage with different machine gauge (yarn count 26/s Ne) 


\section{CONCLUSION}

In this study, an experimental method was carried out to investigate the influence of machine parameters on fabric GSM and shrinkage percentage. It is observed some remarkable changes due to different machine gauge for same yarn count and same machine gauge for coarser and finer yarn count. For dimensional stability shrinkage percentage had a major significance on plain fabric which was found $3 \%$ to $7 \%$ both in lengthwise and widthwise. This study was only covered on plain knitted fabric which can be applied on derivatives of other plain structures

\section{ACKNOWLEDGMENT}

Authors appreciate the generous support from Devine Tex for support in the experimental research.

\section{REFERENCES}

[1] Lyer and Mammel; Schach Characteristics of Circular Knitting Machines, Circular Knitting [Book]. - Bamberg, Germany: Meisenbach GmbH, 1995, pp. 44-45.

[2] Anbumani N., Weft Knit Fabric Geometry. In Knitting Fundamentals, Machines, Structures and Developments [Book]. - New Delhi, New Age International (P) Limited, 2007, pp. 76-86.
[3] Mikučionienè, D.and Laureckienè, G.; The Influence of Drying Conditions on Dimensional Stability of Cotton Weft Knitted Fabrics, Materials Science, 2009, 15, 64-68.

[4] Spencer, David J. Knitting technology, London, Woodhead Publishing Limited, 1987.

[5] Emirhanova N, Kavusturan Y. Effects of knit structure on the dimensional and physical properties of winter outerwear knitted fabrics. Fibers \& Textiles in Eastern Europe. 2008, vol.16(2):69-74

[6] Akaydin M., Characteristics of Fabrics Knitted with Basic Knitting Structures from Combed Ring and Compact Yarn, Indian Journal of Fibre and Textiles, 2009, vol. 34, 26-3

[7] Yesmin, S, Hasan M, Miah, MS; Momotaz, F; Idrish, MA, Effect of stitch length and fabric consruction on dimentional and mechanical propertics of knitted fabrics, World Applied Sciences Journal, 2014, pp. 1991-1995

[8] Eryuruk, S.H.; Kalaoglu, F.; Analysis of the performance properties of knitted fabrics containing elastane, Journal of Clothing Science and Technology, 2016, vol. 28, pp. 463-469.

[9] Yeqiu, L.; Jinlian, H.; Yong, Z.; Zhuohong, Y. Carbohydrate Polymers, 2005, vol. 61, pp. 276.

[10] June Hemmons Hiatt. The Principles of Knitting, Simon and Schuster, 1988.pp. 415-432. ISBN 0-671-55233-3.

[11] Roshan L. S., Importance of Mechanical and Physical Properties of Fabrics in the Clothing Manufacturing Process. International Journal of Clothing Science and Technology, 1995, vol.7, pp.35-42

[12] Chen, Y., and Collier, B. J, Characterizing Fabric End Use by Fabric Physical Properties, Textile Research Journal, 1997, vol. 67, no.4, pp. 247-252

[13] Kang, B. C.and Herath, C. N., Dimensional Stability of Core Spun Cotton/Spandex Single Jersey Fabrics under Relaxation, Textile Research Journal, 2008, vol.78, pp.209- 216 